\title{
Adaptation to three types of water-deprivation schedules in the hooded rat'
}

CHARLES L. KUTSCHER

SYRACUSE UNIVERSITY

Rats allowed a $30 \mathrm{~min}$. or a $180 \mathrm{~min}$. daily drinking period with no food present during this period, showed almost identical daily food intakes and body weight losses even though the latter group drank consistently more during the drinking period than the former. Rats allowed a 180 min. daily drinking period with food present with the water showed higher daily food and water intakes than the other two groups and their body weight stabilized immediately. All groups showed a gradual increase in food and water intake during the 25 days on schedule.

Psychologists often use water-deprivation schedules to maintain experimental animals at a certain level of dehydration or at a certain body weight during the course of a long-term experinient. There are few published papers on the time course of adaptation to these schedules (Beck, 1962; Beck, 1964) or on the course of adaptation as a function of type of schedule. Since there is an interaction between food and water intake in rats (Verplanck \& Hays, 1953), the availability of food on the schedule should affect water intake and the amount of water consumed should affect food intake. In this experiment length of drinking period and food availability were controlled. Adaptation to the schedules was taken to be a stabilization of body weight and an increase in food and water intake as the schedules progressed.

\section{Method}

Ss were 36 male hooded rats from the colonies of the Psychology Department of Syracuse University. They were about 150 days old at the beginning of the experiment and their mean weight was $449.6 \mathrm{gm}$. Ten rats were randomly assigned to each of three types of limited-time water-deprivation schedules on which rats were allowed access to water at the same time each day. Six rats served as a control group and had unlimited access to food and water. The water-deprivation schedules were: (1) 21-hr. schedule on which water was available for $3 \mathrm{hr}$. per day and food was continually available, even during the drinking period (21-F); (2) 21-hr. schedule on which water was available for $3 \mathbf{h r}$. per day and food was always available, except during the drinking period $(21-\mathrm{NF})$; (3) $23.5-\mathrm{hr}$. schedule on which water was available for $30 \mathrm{~min}$. per day and food was continually available, except during the drinking period (23.5-NF).

Rats were removed from the colony and placed in individual $10 \times 8 \times 7$ in. cages constructed of steel and hardware cloth. After three days of adaptation to the cages, food cups, and drinking tubes, four days of baseline food intake, water intake, and body weight measures were taken before the 25-day deprivation schedules began. Rats were maintained on powdered Purina Chow and tap water during the course of the experiment. Water intake was measured with inverted $100 \mathrm{ml}$ graduated cylinders graduated in $1 \mathrm{ml}$ units and fitted with stainless steel drinking nozzles. Food intake was determined by weighing glass, spill-proof food cups which were refilled daily. During the daily drinking period, the water tubes were placed on the cages. Room lights were timed to provide $12 \mathrm{hr}$. of darkness and 12 hr. of light.

\section{Results}

Daily water intakes, food intakes, and body weights were analyzed with the analysis of variance to determine the effects of two variables, time on schedule and type of schedule. All individual measures were grouped into six 4-day blocks for the analysis.

Daily body weight measurements, food intakes, and water intakes are presented in Fig. 1 as percent of the 4-day ad libitum baseline. A one-way analysis of variance run on the sums of these measures for the four ad libitum days revealed no significant differences among the three deprivation groups before the sched-

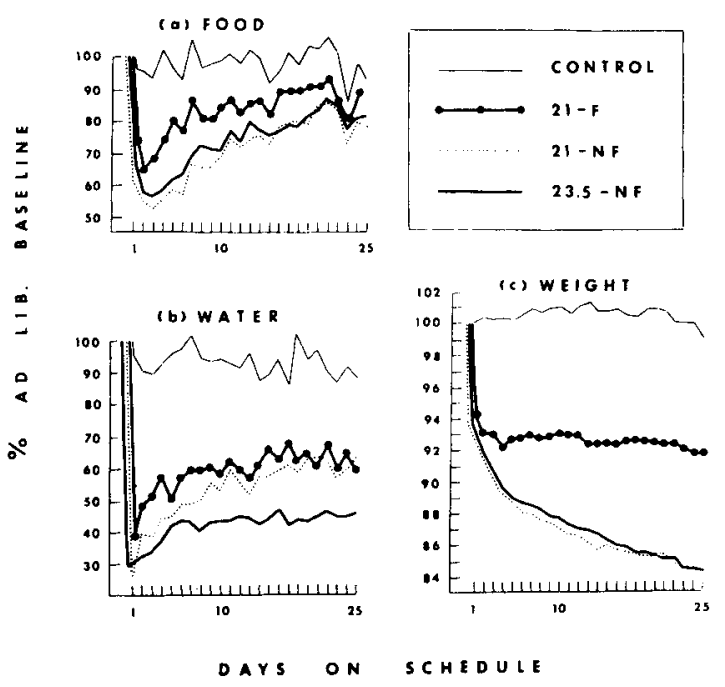

Fig. 1. Mean daily food intake (1a), water intake (1b), and body weight (1c) presented as percent of the 4-day ad libitum baseline for rats on three types of water-deprivation schedules. Control group had water ad libitum. 
ules began. Water intakes on the schedules differed as a function of type of schedule ( $F=158.70, d f=2 / 162$, $p<.01)$ and time on schedule ( $F=40.68, \mathrm{df}=5 / 162$, $p<.01)$. The interaction of the two variables was not significant. Mean daily water intake gradually increased in every group with time on the schedule, but mean daily intake never reached the level of the ad libitum baseline. The 23.5-NF group showed a low, but very stable water intake. Daily water intake was increased by increasing the drinking period from 30 to $180 \mathrm{~min}$. (21-NF group), and was increased still further by allowing food present during the $180 \mathrm{~min}$. drinking period (21-F group). Food intake varied significantly with the type of schedule $(F=63.06, d f=2 / 162, p<.01)$ and with time on the schedule $(F=38.90, \mathrm{df}=5 / 162$, $p<.01)$. Interaction between these two variables was not significant. In spite of the fact that the 21-NF group drank consistently more than the 23.5-NF group, the former showed a slightly lower food intake (Fig. 1a). Every group showed gradually increasing food intake with time on the schedule probably resulting from increased water intakes instead of learning to eat in the face of water deprivation since water-food ratios remain fairly constant for all the groups over the 25 days on schedule. The 21-F group consistently had the highest food intake which rose to more than $90 \%$ of ad libitum baseline during the later part of the schedule. Body weight losses varied with both schedule type $(F=85.44, \mathrm{df}=2 / 162, \mathrm{p}<.01)$ and time on schedule $(F=13.08, d f=5 / 162, p<.01)$. The interaction was not significant. Body weight for the $21-\mathrm{F}$ group stabilized almost immediately. The 21-NF and 23.5-N F group showed consistent and almost identical declines in body weight throughout the 25 days on the schedule.

\section{Discussion}

The 21-F schedule was the least stressful of the three types studied. Since body weight measures were taken before the drinking period, the rats' post-drinking period body weights probably exceeded those of the ad libitum baseline. In terms of food intake, adaptation to any of these schedules takes at least 25 days. Apparently the hooded rat must have a drinking period longer than $3 \mathrm{hr}$. before voluntary food deprivation can be eliminated from the limited-time water-deprivation schedule. These data are contrary to a previous study (Kutscher, 1964) using albino rats and a different type of food. It was surprising that a $3-\mathrm{hr}$. drinking period $(21-\mathrm{NF})$ was no better than a $30-$ min. drinking period $(23.5-\mathrm{NF})$ in terms of food intake and body weight, when no food was given during the drinking period. Even though the 21-NF and 23.5-NF schedules are convenient for the experimenter, their usefulness is limited in cases where the experimenter wants to establish a stable body weight in a short period of time.

\section{References}

Beck, R. C. Some effects of restricted water intake on consummatory behavior of the rat. In M. J. Wayner (Ed.), Thirst. New York: Pergamon, 1964, 305-315.

Beck, R. C. The rat's adaptation to a 23.5 -hour water deprivation schedule. J. comp. physiol. Psychol., 1962, 55, 646-48.

Kutscher, C. Some physiological correlates of adaptation to a water deprivation schedule. In M. J. Wayner (Ed.), Thirst. New York: Pergamon, 1964, 257-267.

Verplanck, w. S., \& Hayes, J. R. Eating and drinking as a function of maintenance schedule. J. comp. physiol. Psychol., 1953, 46, 327-333.

\section{Note}

1. This research was partially supported by U. S. Army Research Contract DA-49-193-MD-2537. 